\title{
The effect of set upon length estimation in active touch perception'
}

JON E. ROECKELEIN, Arizona State University. Tempe. Ariz. 85281

Three groups of Ss performed a task requiring the reproduction of unseen objects which were felt through a curtain. One group $(R T)$ received rod-length training; another group (LT) received letter training: and a third group (NT) received no training. Comparisons of group responses showed that the experimental group $(R T)$ and control groups $(N T, L T)$ differed significantly and demonstrated that a preparatory set involving rod-length estimation could be induced in Ss using active touch perception.

The influence of set upon visual problem-solving and perception has been well-known since the early set experiments (e.g., Külpe, 1904; Sïpola, 1935; Luchins. 1942) and well-reviewed recently (Haber, 1966: Steinfeld, 1967). In the area of tactile perception, however, the effects of set in active touch sensing have not been included among the theoretical and methodological distinctions offered between active and passive touch (e.g., Gibson, 1962).

Vekker \& Lope (1961), using both active and passive touch methods, analyzed Ss' finger movements in the perception of surface length; their results emphasized the importance of the two dimensions of surface texture and finger movement duration upon estimation of surface length. The purpose of the present study was to investigate, via active touch methods. the phenomenon of preparatory set and the effects of set upon surface length estimation.

\section{METHOD}

Students in an undergraduate general psychology course served as Ss. There were three groups of Ss with six students in each group. In the "Rod Training" group (RT). Ss were given a training phase of eight trials which consisted of their making estimations of the lengths of wooden rods. In the "Letter Training" group (LT), Ss were given a training phase of eight trials which consisted of their making identifications of letters of the alphabet plus spelling words with children's play block letters. During the training phases of both groups, RT and LT. feedback was given and correct responses were verbally reinforced by E with the words "Good!" or "Yes, that's right!." In the third group, "No Training" (NT), no training phase was given. LT and NT were considered to be control groups. RT was considered to be the "task-induced preparatory set" or experimental group. All stimulus objects were handled and felt by $S$ and none was seen: a large curtain through which $S$ put his hands was hung between $S$ and $E$ and prevented $S$ from viewing the stimuli. After the training phase, RT and LT received a testing phase (NT received only the testing phase) which required Ss to feel stimulus objects with their hands and then to reproduce what they "felt" by drawing the design on paper. Thus, $S$ s in all groups, RT. LT. and NT, were given the same testing session. The testing stimulus objects consisted of six designs; each design was in the shape of a letter of the alphabet and was constructed of wooden dowels glued to a wooden base. The block letters T, A. $M, E, H$, and $K$ were used. There was a $1 / 4-i n$. gap in the dowels at one regular, straight place (i.e., at nonangular or noncircular loci) in each design. Designs differed in the ratio of dowel lengths on either side of the gap; the ratios of the two lengths were $1: 1,1: 2,1: 3,1: 4,1: 5$, and $1: 6$.

\section{RESULTS}

The dependent variable which $\mathrm{E}$ measured was the ratio of the lines on both sides of the gap. which $\mathbf{S}$ showed in his reproductions after touching and handling the various stimulus objects. In all, each $\mathrm{S}$ was given an opportunity to make eight reproductions during the testing phase for a total of 48 measures per group. Measurements of dowel lengths were made in 1/10th-in. units. The means and SDs of drawing responses made by $S s$ in each of the three groups were calculated and tests were run for the groups. In addition, the mean and SD of the "correct" or "objective" rod lengths of the testing stimuli were computed. This latter step was taken in order to juxtapose Ss' responses with an "absolute" criterion along with the relative comparisons permitted by the between-group treatments. Table 1 shows the means and SDs of the group scores. Table 2 shows the significance levels using $t$ tests for the various group comparisons.

It should be mentioned that out of 48 drawings which were possible for each group, the following numbers of responses per indicated group were omitted from the data because of the absence of a measurable gap in Ss' design reproductions: $R T$-two responses; NT-two responses: $L T-n i n e$ responses.

\section{DISCUSSION}

The present study was successful in the attempt to induce in Ss a preparatory set involving rod length through the use of an active touch methodology. Tables 1 and 2 show that the experimental group (RT) is significantly different from both control groups (LT, NT) and the estimations of rod length made under RT conditions were closer to the "objective," "correct." or "actual" (CL) rod lengths and ratios than were estimations made under LT or NT conditions. It should be noted. however, that of the two control groups, LT was more similar than NT to CL conditions. Perhaps it was true that the nature of the task employed during training for LT was strong enough to cause-on an "unconscious" level-the greater "availability" (cf: Steinfeld. 1967, p. 520) of length traces which were used during the testing phase. Since Ss in LT had some contact during training with stimuli which was "roughly" similar to the testing stimuli-although not the specific contact that Ss in RT were given-this may have benefited the responses made during the testing phase. Along this line, it should also be noted that of the three groups (RT. LT, and NT). LT produced nine unusable responses (i.e.. there were no measurable gaps in drawings at the correct places

Table 1

Means and SDs of Group Data for Actual (CL) and Estimated (RT LT, NT) Rod Lengths

\begin{tabular}{lcc}
\hline Group & Mean (in.) & SD \\
\hline $\begin{array}{l}\text { Correct Length } \\
\text { (CL) }\end{array}$ & 3.50 & \\
Rod Training & 3.99 & 1.70 \\
$\quad$ (RT) & 2.47 & 1.17 \\
$\begin{array}{l}\text { Letter Training } \\
\text { (LT) }\end{array}$ & 2.10 & 1.21 \\
No Training & & 1.25 \\
\hline (NT) & & \\
\hline
\end{tabular}

Table 2

Significance Levels for Group Comparisons of Rod Length Estimations

\begin{tabular}{llcl} 
& (RT) & (LT) & (NT) \\
\hline (CL) & N.S. & N.S. & $\mathrm{p}=.10$ \\
(RT) & & $\mathrm{p}=.05$ & $\mathrm{p}=.01$ \\
(LT) & & & N.S. \\
\hline
\end{tabular}


around which to compute a rod ratio) as compared with two unusable responses each for RT and NT. Theoretically, the question might be asked: Were Ss in the LT group "cognitively confused" by letter training at one point (training) and rod length estimating at another point (testing)? Properly conceived research regarding this question may eventually offer an answer; but whatever the answer, the results of the present study stand in demonstrating that task-induced set is possible to achieve within the area of active touch perception.

\section{REFERENCES}

GIBSON, J. J. Observations on active touch. Psychological Review, 1962, $69,477-491$.

HABER, $R$. N. The nature of the effect of set on perception. Psychological Review, 1966, 73, 335-350.

KULPE, O. Versuche uber Abstraktion. Berlin International Congress of Experimental Psychology, 1904, 56-68.
LUCHINS, A. Mechanization in problem-solving: The effect of Einstellung. Psychological Monographs: General \& Applied, 1942, 54, 6. (Whole No. 248.)

SIIPOLA, E. M. A group study of some effects of preparatory set. Psychological Monographs: General \& Applied, 1935, 46, 6. (Whole No. 210.)

STEINFELD, G. J. Concepts of set and availability and their relation to the reorganization of ambiguous pictorial stimuli. Psychological Review, 1967, 74, 505-522.

VEKKER, L. M., \& LOPE, YU. P. On the problem of the formation of tactual images. Voprosy Psikhologii, 1961, 5, 143-153. E245

NOTE

1. The author wishes to thank James E. Scoresby for providing subjects and Joyce E. Pattison for her assistance in the preparation and critical reading of the manuscript.

\section{Notes and News}

At its recent meeting in St. Louis, the Governing Board of the Psychonomic Society voted to authorize this Journal to carry a section on Notes and News. This we are beginning to do with the current issue. The section will carry notices of changes of position for members of the Society as well as other news of interest to subscribers and to members. You are invited to send us items which you believe would be suitable for the section. Our first item is as follows:

The American Journal of Psychology is pleased to announce that Charles W. Eriksen and Benton J. Underwood have accepted invitations to become principal editors of the Journal. Edwin B. Newman and M. E. Bitterman continue asprincipal editors. Lloyd G. Humphreys replaced Karl M. Dallenbach as Managing Editor when the ownership of the Journal was transferred to the University of Illinois.

Members of the Psychonomic Society are eligible for the same subscription rate for the American Journal of Psychology that is available to members of the American Psychological Association. The current rate is $\$ 5$ for a volume of approximately 600 pages. 